\title{
Water use dynamics of young and mature apple trees planted in South African orchards: a case study of the Golden Delicious and Cripps' Pink cultivars
}

\author{
Zanele Ntshidi $^{1,2}$, Sebinasi Dzikiti ${ }^{2}$, and Dominic Mazvimavi ${ }^{1}$ \\ ${ }^{1}$ Department of Earth Sciences, University of the Western Cape, Bellville 7535, South Africa \\ ${ }^{2}$ Council for Scientific and Industrial Research, Natural Resources and Environment, \\ Stellenbosch 7600, South Africa \\ Correspondence: Zanele Ntshidi (zntshidi@gmail.com)
}

Received: 10 November 2017 - Accepted: 22 December 2017 - Published: 29 May 2018

\begin{abstract}
Apple orchards have previously been bearing $60-80 \mathrm{tha}^{-1}$ at most. However in recent years yield has increased to more than $100 \mathrm{tha}^{-1}$. There is need to understand the water requirements of the high yielding orchards, given that high crop loads are associated with high water use rates. The aim of this study was to quantify the water requirements of young and mature unstressed apple orchards. We also assess the impact of climate variables on transpiration rates. Data was collected in 4 orchards in the Western Cape Province. The orchards comprised young non-bearing ( $<3$ years) and mature trees planted to the Golden Delicious and Cripps' Pink cultivars, all under micro-sprinkler irrigation. Transpiration by the trees was measured using heat pulse velocity sap flow sensors hourly throughout the growing season (October-June). Weather was monitored using an automatic weather station. Tree transpiration was linearly related to the solar radiation, but the relationship with the vapour pressure deficit (VPD) was non-linear. There were no significant differences $(p>0.05)$ in the sapflux density of the Golden Delicious and Cripp's Pink cultivars. This suggests that these two cultivars have similar water use characteristics. Mature orchards transpired between 6000 to $8000 \mathrm{~m}^{3} \mathrm{ha}^{-1}$ season $^{-1}$ while nonbearing orchards used between 2000 to $3000 \mathrm{~m}^{3} \mathrm{ha}^{-1}$ season $^{-1}$.
\end{abstract}

\section{Introduction}

South Africa is currently the 7th biggest exporter of apples (Malus domestica Borkh.) in the world. The main Southern hemisphere competitor is Chile, which is ranked third in terms of export. In South Africa, most apples are grown in the Eastern and Western Cape Provinces. The Western Cape experiences Mediterranean climatic conditions and most of the rain falls outside the fruit growing season in winter. This region is projected to experience severe water shortages in future due to the rapidly increasing population, increasing agricultural and industrial activities and climate change (Midgley and Lötze, 2011). Accurate information on water use by apple orchards is therefore critical for the sustainability of the multi-billion Rand deciduous fruit industry. This information will be useful for, among other things: (1) developing irrigation scheduling guidelines for the apple industry, (2) water al- location and planning, and; (3) developing strategies for coping with drought whose frequency and severity is expected to increase in the near future in the South Western parts of the country. Severe water deficits imposed by a lack of irrigation not only reduce the current year's yields, but they also negatively affect production in subsequent years, enhance alternate bearing and damage or kill trees (Fereres et al., 2012). An important information gap currently exists regarding the water requirements of high yielding $\left(\geq 100 \mathrm{tha}^{-2}\right)$ apple orchards which have become the norm in this region in recent years. There is also no published information on how water use varies with orchard growth stages from planting until full-bearing. Although several studies have quantified water use by apple orchards (Braun et al., 2000; Volschenk et al., 2003; Dragoni et al., 2005; Gush and Taylor, 2014) these studies were not done in exceptionally high yielding orchards. The specific objective of the study was to quan- 
tify how transpiration of apple orchards change with canopy cover, to facilitate the development of irrigation guidelines. An example of a programme in which the fruit industry could directly benefit from the data generated in this study is the recently launched Validation and Verification of Lawful Water Use $(\mathrm{V} \& \mathrm{~V})$ programme. This programme has been rolled out throughout South Africa by the Department of Water and Sanitation (DWS) mainly to confirm how much water may be used lawfully for commercial purposes (including irrigation) to facilitate water use licensing in line with the country's Water Act of 1998. Therefore, this study sets a benchmark on the water requirements of the country's most productive apple orchards.

\section{Materials and Methods}

\subsection{Study sites}

Four orchards (two non-bearing and two full-bearing) were monitored in the Koue Bokkeveld (KBV) region during the 2014/15 growing season. Yield in all full-bearing orchards was consistently above $100 \mathrm{t} \mathrm{ha}^{-1}$. The full-bearing "Cripps' Pink" and "Golden Delicious" orchards were in adjacent blocks KP06 and KP07 at Kromfontein Farm in the Koue Bokkeveld (S32.97120; E019.23295 ; $876 \mathrm{~m}$ a.s.1.). They were both ca. 6 ha in size and aged 22 years for the "Golden Delicious" and 9 years for the "Cripps' Pink". They had similar soil types namely the deep sandy Fernwood soils with approximately $30 \%$ stone. Tree spacing in both orchards was $4 \mathrm{~m} \times 1.5 \mathrm{~m}$ giving a plant density of 1667 trees per hectare. Rootstock in both orchards was the industry standard M793. Both orchards were irrigated with medium range micro sprinkler systems.

The non-bearing "Golden Delicious" orchard was at Lindeshof Farm (S32.95002 ${ }^{\circ}$; E019.20737 ; 820 m a.s.1.), less than $2 \mathrm{~km}$ from Kromfontein. Both farms belong to $\mathrm{Du}-$ toit Agri and therefore they had similar management practices. The non-bearing "Golden Delicious" orchard was two years old and it was about 3.17 ha in size. The rootstock was also the M793 and the trees were planted in rows with a north-south orientation. Tree spacing and soil types were similar to that of the full bearing orchards. The nonbearing "Cripps' Pink" orchard was at Paardekloof farm (S32 ${ }^{\circ} 5^{\prime} 39.02^{\prime \prime}$; E019 ${ }^{\circ} 16^{\prime} 00.74^{\prime \prime}$; $900 \mathrm{~m}$ a.s.1.) on MM109 rootstock. The Paardekloof orchard was about 6.3 ha, but trees were planted at $3.5 \mathrm{~m} \times 1.25 \mathrm{~m}$ giving a substantially higher plant density of 2285 trees per hectare. The trees were three years old and also growing on deep sandy soils irrigated with a medium range sprinkler system.

\subsection{Climate data}

Weather data was measured using an automatic weather station in close proximity to the orchards. The station was installed at a site with uniform short grass cover whose at- tributes were close of those of the grass reference surface (Allen et al., 1998). The equipment comprised a pyranometer (Model: SP 212 Apogee Instruments, Inc., Logan UT, USA), which measured the solar irradiance and it was installed on a north facing horizontal levelling fixture to avoid self-shading and to minimize cosine errors. Air temperature and relative humidity were measured using a temperature and humidity probe (Model: HMP60 Campbell Scientific, Inc., Logan UT, USA) installed at a height of about $2.0 \mathrm{~m}$ above the ground. Rainfall was recorded using a tipping bucket rain gauge (Model: TE525-L; Campbell Scientific, Inc., Logan UT, USA). All the sensors were connected to a data logger (Model: CR1000 Campbell Scientific, Inc., Logan UT, USA) programmed with a scan interval of $10 \mathrm{~s}$ and the output signals were processed at hourly and daily intervals, respectively.

\subsection{Tree water use}

Transpiration in each of the full-bearing orchards was measured from September 2014 until June 2015 on six trees of different stem sizes using the heat ratio method of the heat pulse velocity (HPV) sap flow technique (Burgess et al., 2001). Four sets of heater probes and T-type thermocouple pairs were inserted into the sap wood of the stems at depths ranging from 10 to $50 \mathrm{~mm}$ under the bark, depending on the size of the stem, to account for the circumferential and radial variation in sap velocity (Wullschleger and King, 2000). The HPV data was corrected for wounding, moisture fraction and wood density at the end of the experiment according to the approach by Swanson and Whitfield (1981). The wound widths were measured at five positions across the length of the wound created by sensor implantation using Vernier callipers. The conducting sapwood area was determined by injecting a weak solution of methylene blue dye into the stems towards the end of the experiment to determine the extent of the active xylem vessels. The bark-sapwoodheartwood boundaries were clearly distinguishable with this method. Transpiration by the smaller trees in the non-bearing orchards was measured using Granier probes (Model: TDP 10, Dynamax Inc., Houston, USA) (Granier, 1987). Three trees were instrumented per orchard and the average sap velocity was determined in the depth range 0 to $10 \mathrm{~mm}$ of the stems. The sensors were installed at a height between 50 and $75 \mathrm{~cm}$ from the ground to eliminate errors due to cold sap especially early in the morning. Installing the sensors at the recommended $1.0 \mathrm{~m}$ height above the ground was not feasible because the trees branched close to the ground. A double layer of aluminium bubble wrap was wrapped around the sensors to minimize the effects of exogenous heating on the sap temperature signals. The TDP sensors were calibrated against the more accurate stem heat balance sap flow sensors given the tendency of TDPs to underestimate transpiration rates (Steppe et al., 2010). Both the TDP and HPV sap flow 

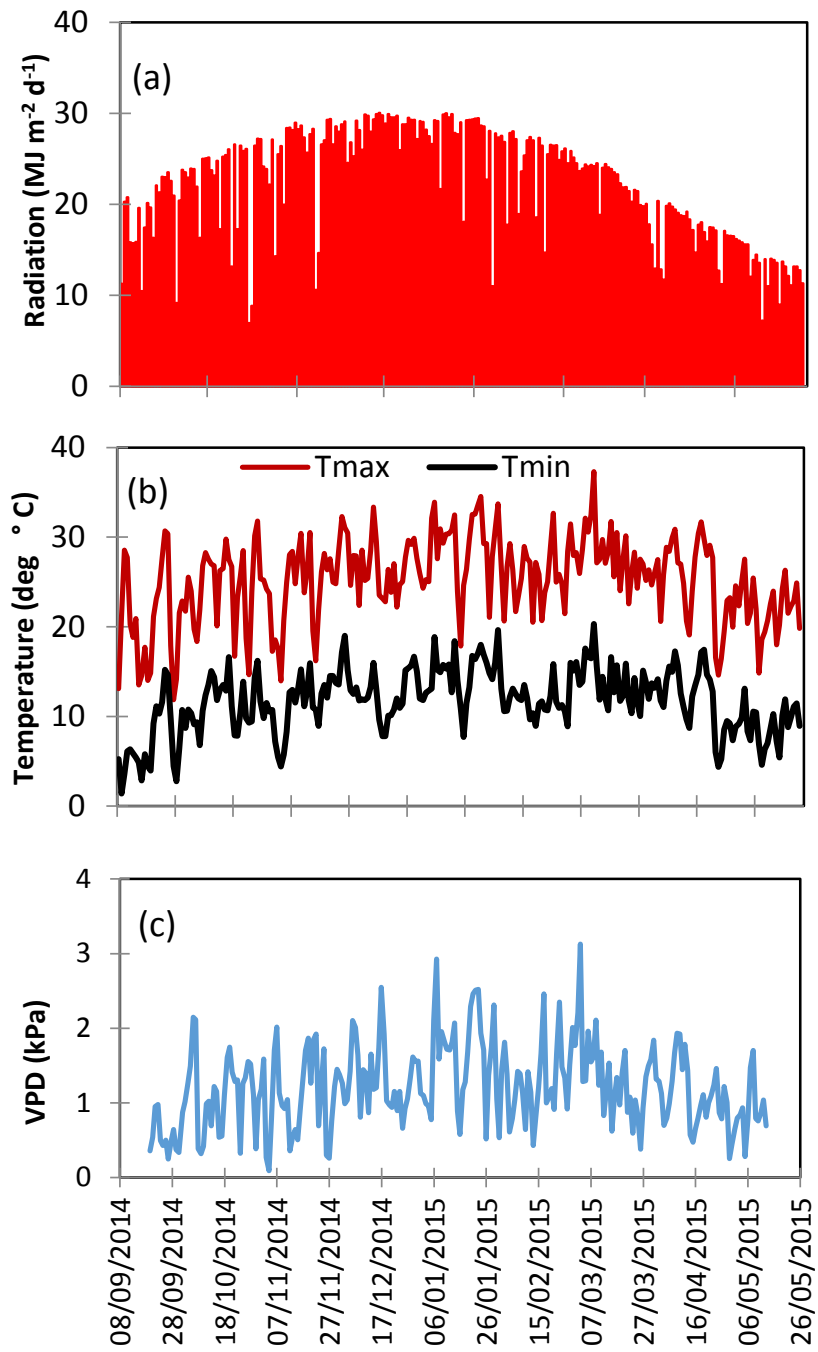

Figure 1. (a) Solar radiation, (b) minimum and maximum temperature and (c) Vapour Pressure Deficit from September 2014 to May 2015.

data was collected at hourly intervals throughout the study period (i.e. September 2014 to June 2015 in KBV).

\subsection{Statistical analysis}

Differences in the sapflux density (sapflow per unit sapwood area) were compared between the two cultivars using one way analysis of variance ( $t$ test) with $\alpha=0.05$.

\section{Results and discussion}

The maximum daily solar radiation was $30.02 \mathrm{MJ} \mathrm{m}^{-2} \mathrm{~d}^{-1}$ recorded on 17 December 2014 and the lowest was $6.9 \mathrm{MJ} \mathrm{m}^{-2} \mathrm{~d}^{-1}$ measured on 2 November 2014. December 2014 had the highest average daily solar radiation of approx. $28.3 \mathrm{MJ} \mathrm{m}^{-2}$. The maximum and minimum air temperatures were 37.3 and $1.4{ }^{\circ} \mathrm{C}$ reached in December 2014

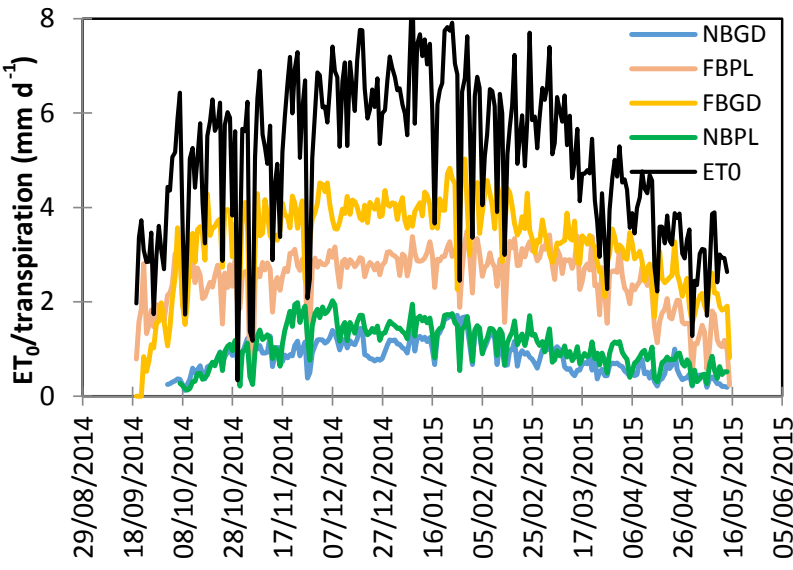

Figure 2. Water use of the young and mature apple trees and the reference evapotranspiration.

and June 2015 , respectively. The maximum air temperature exceeded $30^{\circ} \mathrm{C}$ in seven of the nine months. The relative humidity ranged from $99.9 \%$ to as low as $5.4 \%$ on hot dry days with the vapour pressure deficit of the air peaking at $3.1 \mathrm{kPa}$ (Fig. 1). The reference evapotranspiration $\left(\mathrm{ET}_{o}\right)$, which is a measure of the atmospheric evaporative demand, was calculated as the evapotranspiration from a short grass reference using the modified Penman-Monteith equation according to Allen et al. (1998). The seasonal total reference evapotranspiration was $1205.4 \mathrm{~mm}$. Transpiration for the full bearing "Golden Delicious" trees peaked at $5 \mathrm{~mm} \mathrm{~d}^{-1}$, while the similar size trees of the Cripps' Pink cultivar peaked at $3.5 \mathrm{~mm} \mathrm{~d}^{-1}$ at the end of January 2015. The non-bearing "Golden Delicious" and Cripps' Pink trees transpiration peaked at 1.7 and $2.02 \mathrm{~mm} \mathrm{~d}^{-1}$ (Fig. 2) on 25 January 2015 and 6 December 2014, respectively. The seasonal total for the full-bearing "Golden Delicious" was $770 \mathrm{~mm}$ while for "Cripps' Pink" it was $587 \mathrm{~mm}$. The non-bearing "Golden Delicious" trees transpired a seasonal total of $187 \mathrm{~mm}$ while "Cripps' Pink" transpired $238 \mathrm{~mm}$ for the season. Variations in transpiration rates in full-bearing orchards were a result of differences in canopy management practices between the "Golden Delicious" and "Cripps' Pink" orchards. "Cripps' Pink" canopies are kept open e.g. by pruning and spraying shoot growth retardants such as Regalis ${ }^{\circledR}$ to expose the fruit to solar radiation for anthocyanin synthesis to occur and to promote the development of the red fruit colour. The leaf area index (LAI) for the full bearing "Golden Delicious" was $\sim 3.5$ while for the "Cripps' Pink" it was $\sim 2.8$. For nonbearing orchards it was 0.8 for "Golden Delicious" and 1.0 for "Cripps' Pink". Canopy cover seems to be the main driver of water use, the bigger the canopy, the more water the tree uses. The daily total transpiration was linearly related to the daily solar radiation (Fig. 3a and b). However, the relationship between transpiration and VPD (Fig. $3 \mathrm{c}$ and d) was non- 

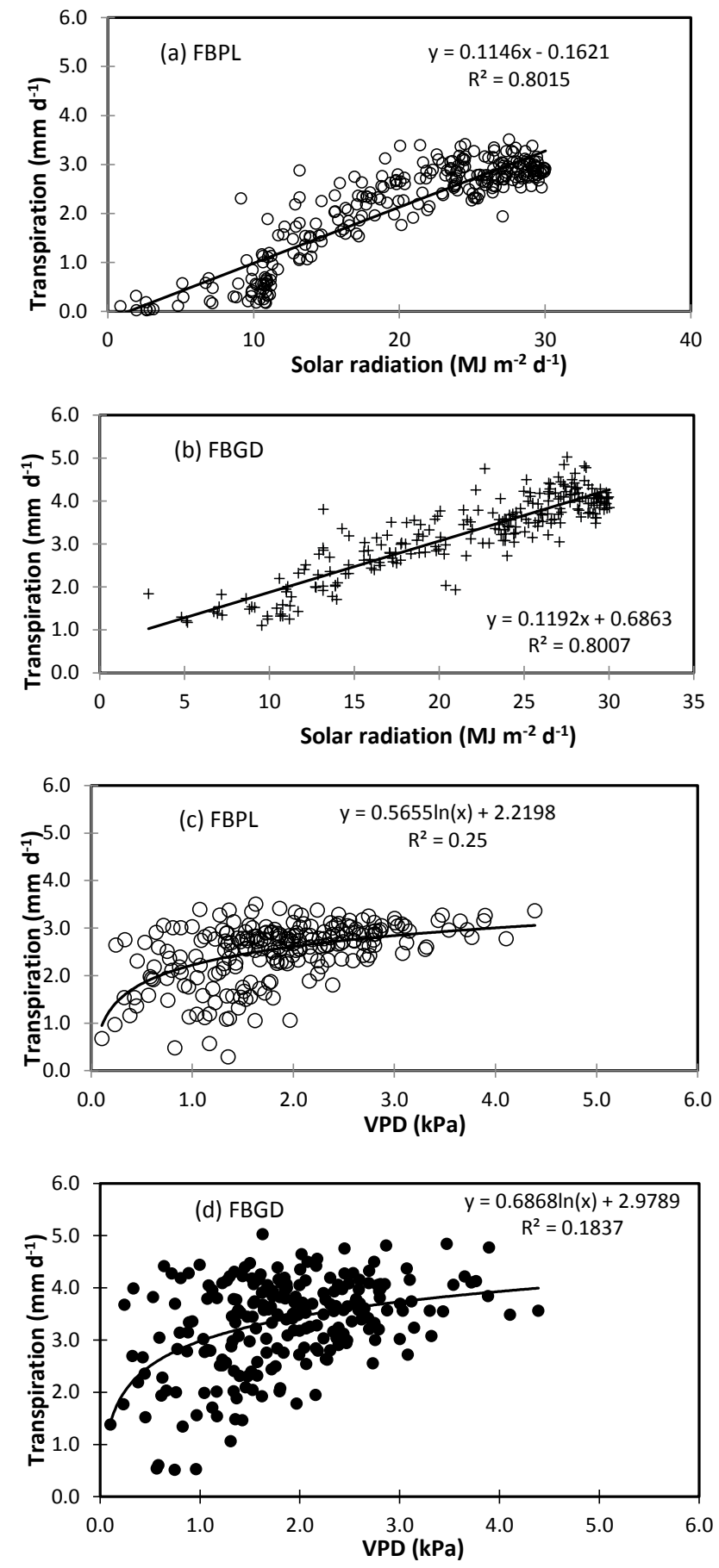

Figure 3. Transpiration response of full-bearing (a) "Cripps' Pink" to solar radiation, (b) "Golden Delicious" to solar radiation, (c) "Cripps' Pink" to VPD (d) "Golden Delicious" to VPD. linear, suggesting that the VPD is the most limiting variable for apple trees transpiration.

\section{Conclusions}

This study provides first estimates of the water use characteristics of apple trees considering newly planted and mature trees. For mature trees, it appears that "Cripps' Pink" trees tend to use less water than "Golden Delicious". This is because they tend to have more open canopies due to management practices e.g. the spraying of chemicals such as Regalis ${ }^{\circledR}$ to reduce shoot growth. Dense foliage is not favourable for the development of the red colour on fruit in red and blushed cultivars and these canopy management practices appear to have water saving benefits. In nonbearing trees, the Cripps' Pink cultivar seems to be using more water than the "Golden Delicious". Transpiration was linearly related to the solar radiation, while VPD seemed to be a limiting variable for water use.

Data availability. The Water Research Commission (WRC) has all the rights to the data as they are the funders. Their policy supports that data be made public. However, this project is still ongoing, therefore no data is made available yet. When the project has been finalized, the data will be available at www.wrc.org.za.

Competing interests. The authors declare that they have no conflict of interest.

Special issue statement. This article is part of the special issue "Understanding spatio-temporal variability of water resources and the implications for IWRM in semi-arid eastern and southern Africa". It is a result of the IAHS Scientific Assembly 2017, Port Elizabeth, South Africa, 10-14 July 2017.

Acknowledgements. This project was initiated, supported and managed by the Water Research Commission (project no WRC K5 2398/4) and the South African Apple and Pear Producers' Association (SAAPPA). We are sincerely grateful for the financial support from these entities. Additional South African Parliamentary Grant funding through the Council for Scientific and Industrial Research (project number ECHS 043) and CSIR Young Researcher Establishment Fund (project ECHS 074) are also greatly acknowledged.

Edited by: Webster Gumindoga

Reviewed by: Timothy Dube and one anonymous referee 


\section{References}

Allen, R. G., Pereira, L. S., Raes, D., and Smith, M.: Crop evapotranspiration, FAO irrigation and drainage paper 56, Food and Agriculture Organization, Rome, Italy, 1998.

Braun, P., Maurer, B., and Heinemann, G.: Scaling transpiration in apple orchards-meteorological versus plant based physiological measurements, Acta Hort., 537, 45-51, 2000.

Burgess, S. S. O., Adams, M. A., Turner, N. C., Beverly, C. R., Ong, C. K., Khan, A. A. H., and Bleby, T. M.: An improved heat pulse method to measure low and reverse rates of sap flow in woody plants, Tree Physiol., 21, 589-598, 2001.

Dragoni, D., Lakso, A. N., and Piccioni, R. M.: Transpiration of apple trees in a humid climate using heat pulse sap flow gauges calibrated with whole-canopy gas exchange chambers, Agr. Forest Meteorol., 130, 85-94, 2005.

Fereres, E., Goldhamer, D. A., and Sadras, V. O.: Yield responses to water of fruit trees and vines, UN Food and Agriculture Organisation, Rome Italy, 246-497, 2012.

Granier, A. R.: Evaluation of transpiration in a Douglas fir stand by means of sap flow measurements, Tree Physiol., 3, 309-320, 1987.
Gush, M. B. and Taylor, N. J.: The water use of selected fruit tree orchards (Volume 2): technical report on measurements and modelling, Water Research Commission report no. 1770/2/14, WRC, Pretoria, South Africa, 2014.

Midgley, S. J. E. and Lötze, E.: Climate change in the western cape of South Africa: trends, projections and implications for chill unit accumulation, Acta Hort., 903, 1127-1133, 2011.

Steppe, K., De Pauw, D. J. W., Doody, T. M., and Teskey, R. O.: A comparison of sap flux density using thermal dissipation, heat pulse velocity and heat field deformation methods, Agr. Forest Meteorol., 150, 1046-1056, 2010.

Swanson, R. H. and Whitfield, D. W. A.: A numerical analysis of heat pulse velocity theory and practice, J. Exp. Bot., 32, 221-239, 1981.

Volschenk T., De Villiers, J. F., and Beukes, O.: The selection and calibration of a model for irrigation scheduling of deciduous fruit orchards, WRC report 89, 2003.

Wullschleger, S. D. and King, W. K.: Radial variation in sap velocity as a function of stem diameter and sapwood thickness in yellowpoplar trees, Tree Physiol., 20, 511-518, 2000. 